\title{
Pelo resgate da memória documental das ciências e da agricultura: o acervo do Instituto Biológico de São Paulo
}

\author{
Towards a recovery of the documental memory of sciences and \\ agriculture: the Instituto Biológico de São Paulo's collection
}

Márcia Maria Rebouças

Pesquisadora do Instituto Biológico de São Paulo

Av. Conselheiro Rodrigues

Alves, 1252

04014-002 São Paulo - SP - Brasil

reboucas@biologico.sp.gov.br
REBOUÇAS, M. M.: Pelo resgate da memória documental das ciências e da agricultura: o acervo do Instituto Biológico de São Paulo.

História, Ciências, Saúde-Manguinhos,

Rio de Janeiro, v. 13, n. 4, p. 995-1005, out.-dez. 2006.

O presente trabalho faz um breve inventário do acervo documental do Instituto Biológico de São Paulo, de como se constituiu e sua relevância para as pesquisas em história das ciências no Brasil. A partir de um sucinto histórico da instituição, torna-se possível visualizar sua atuação no campo da pesquisa agronômica em São Paulo. Além de permitir dimensionar o papel das ciências na modernização da agricultura paulista, o acervo do Instituto Biológico reúne documentos de cientistas importantes de nossa história, como Arthur Neiva, Henrique da Rocha Lima e José Reis.

PALAVRAS-CHAVE: acervos documentais; pesquisa agrícola; Instituto Biológico de São Paulo.

REBOUÇAS, M. M.: Towards a recovery of the documental memory of sciences and agriculture: the Instituto Biológico de São Paulo's collection.

História, Ciências, Saúde-Manguinhos,

Rio de Janeiro, v. 13, n. 4, p. 995-1005, Oct.-Dec. 2006.

This brief inventory of the Biological Institute of São Paulo's documental collection describes how the archive came to be and explains its relevance to history of sciences research in Brazil. A short history of the institution provides insight into its activities in the field of agronomic research in São Paulo and the role that sciences played in modernizing agriculture in that state. The collection contains documents by scientists whose names occupy a special place in the history of Brazil, such as Arthur Neiva, Henrique da Rocha Lima, and José Reis.

KEYWORDS: documental collections; agricultural research; Instituto Biológico de São Paulo. 
$\mathrm{A}$ historiografia das ciências no Brasil, ao seguir a tendência de valorizar a concepção contextual de ciência, entendida como forma de conhecimento profundamente vinculada ao ambiente sociocultural no qual está inserida, abriu possibilidades de utilização de uma série de fontes documentais que se revelam úteis para a compreensão de como se estruturava a atividade científica no passado. Sem se deter nos registros de caráter memorialístico e hagiográfico produzidos pelos próprios cientistas, os historiadores da ciência se vêem diante da necessidade de resgatar fontes que permitam acesso mais integral à dinâmica de construção do conhecimento científico, levando em conta aspectos que revelem, ao invés de uma trajetória linear e cumulativa de 'fatos', um percurso marcado por insucessos, disputas e controvérsias.

A busca e valorização de fontes até então negligenciadas pela história das ciências integra-se ao movimento mais geral de redefinição dessa área, conflagrado pelo enquadramento de novos objetos a partir de novos enfoques e questionamentos. Desse modo, a história das ciências ampliou seu escopo através da incorporação de objetos até então alheios à sua problemática canônica, em sintonia com a tendência lançada por March Bloch e Lucien Febvre de estudar práticas negligenciadas pela história tradicional (Pestre, 1996).

Não comprometidos em conservar um ideal mitificador da ciência, os historiadores são chamados a perseguir novos caminhos que apontem a dimensão social e o contingenciamento histórico da atividade científica. Enquanto espaços de produção do conhecimento, as instituições emergem como objetos privilegiados de análise histórica, nos quais são construídos discursos e práticas científicos. As instituições são abordadas numa lógica totalizante, que revela as estratégias de legitimação subjacentes aos processos de realização e divulgação das atividades científicas. Além dos atores envolvidos na produção do conhecimento científico, seus canais de ação e interlocução são levados em consideração, bem como os espaços nos quais tal atividade é desenvolvida e propagada. Esferas superpostas e muitas vezes conflitantes se combinam nessa análise global dos espaços de produção das ciências, que envolve a dimensão privada dos atores, a negociação com os poderes políticos e sociais e os dispositivos de legitimação encetados frente aos pares e representados pelas publicações especializadas.

Recentemente, alguns estudos têm focado a história das instituições científicas, apontando-as como núcleos em que se entrecruzam os diversos elementos atuantes no 'fazer ciência'. Não se preocupando em constituir um panegírico de personalidades heróicas, nem uma imagem imaculada e mitificada das instituições analisadas, tais estudos afirmam a história institucional como im-portante tendência da historiografia das ciências no Brasil. Contudo, os estudos de instituições científicas esbarram na escassez e dispersão de fontes docu- 
mentais, já que muitas não se preocuparam em conservar os registros de sua história, preferindo assentar a memória a partir de relatos laudatórios produzidos por seus próprios quadros. Tais relatos das trajetórias institucionais, através de uma narrativa linear que privilegia os 'grandes feitos' dos personagens ilustres, tendem a apagar os conflitos e vicissitudes do passado, elucidativos da maneira com que se deu o processo de construção e validação dos fatos científicos. Ao se basearem nesses registros, que contudo atuam como fontes importantes de informação, os historiadores correm o risco de endossar a memória institucional francamente comprometida com uma visão idealizada, que na maioria das vezes escamoteia as tensões e negociações constitutivas da prática das ciências.

Muitos chamaram a atenção para o descaso com que são tratados os registros documentais das instituições e para a falta de uma política sistemática de organização e disponibilização desses acervos. As precárias condições de acondicionamento aliadas à absoluta falta de organização das fontes dispostas em locais muitas vezes insalubres para o pesquisador constituem entraves não desprezíveis à tarefa destes. Tais condições muitas vezes inviabilizam a pesquisa dos documentos, deixando-se de analisar fontes relevantes para o desenvolvimento dos estudos. Se hoje o historiador não resume seu trabalho à compilação e à análise crítica de fontes em busca de um retrato fiel do passado, elas mantêm seu papel capital na configuração do tema de pesquisa. A dificuldade ou mesmo impossibilidade de trabalhar com o acervo de muitas instituições científicas obriga o pesquisador a recorrer a fontes alternativas, de modo a sanar a deficiência de não se analisar o corpo documental da própria instituição que é objeto de estudo. Maria Rachel Fróes da Fonseca (2002), ao tratar das fontes para a história das ciências biomédicas no Brasil, destacando sua dispersão e o estado de abandono e deterioração a que estão submetidos muitos acervos, adverte: "A ausência de instrumentos de pesquisa específicos reduz o volume de investigações e, conseqüentemente, paralisa a produção de conhecimentos sobre a história da medicina no país" (p. 285).

Reginaldo Meloni (1999), em estudo sobre o Instituto Agronômico de Campinas no período de 1887 a 1897, ressaltou a impossibilidade de trabalhar com os documentos empilhados nos porões da instituição e a necessidade que teve, de recorrer aos relatórios anuais e periódicos, dispersos em diversos arquivos e bibliotecas. Daí relata a incursão que teve de fazer a centros de pesquisa em São Paulo, Campinas e Rio de Janeiro, a fim de constituir um núcleo de fontes com o qual pudesse desenvolver seu trabalho.

É diante desse cenário que nos propomos a divulgar o acervo do Instituto Biológico de São Paulo, ainda em fase de tratamento e organização, como subsídio para aqueles que buscam estudar temas como a história da agricultura paulista, da pesquisa agropecuária, 
a trajetória da própria instituição ou de quadros que a ela pertenceram. Para tanto, partiremos de breve digressão sobre a história do Instituto Biológico e sua relevância para a história das ciências no Brasil, seguida de um histórico de como se deu a reunião dos documentos que hoje constituem o acervo do qual tratamos.

\section{O Instituto Biológico: origens e trajetória institucional}

As origens do Instituto Biológico remontam à crise fitossanitária representada pela broca do café, praga que acometeu os cafezais paulistas e que levou à constituição, pelo governo paulista, em 1924, de uma comissão científica voltada para combatê-la. Chefiada pelo médico baiano Arthur Neiva, a Comissão de Estudo e Debelação da Praga Cafeeira baseou sua campanha em amplo trabalho de divulgação científica e extenso aparato de fiscalização e controle, no qual praticamente toda a produção cafeeira foi submetida a vigilância. Inicialmente criada como órgão provisório, a Comissão assumiu caráter permanente a partir da lei 2020, de 26 de dezembro de 1924, regulamentada em decreto pelo governador Carlos de Campos em 1925. Com organograma, instalações e orçamento próprios, a Comissão de Estudo e Debelação da Praga Cafeeira, que teve entre seus membros os agrônomos Edmundo Navarro de Andrade e Adalberto Queiroz Telles, atuou como instituição científica anexa à Secretaria de Agricultura, Comércio e Obras Públicas, pasta chefiada por Gabriel Ribeiro dos Santos.

A cronicidade assumida pela broca, associada à sua difusão pelos cafezais do interior paulista, confirmando as assertivas de Arthur Neiva, fizeram que a atuação da Comissão se tornasse cada vez mais proeminente. A Comissão de Estudo e Debelação da Praga Cafeeira passou a atender consultas de lavradores provindas de vários estados do Brasil, extrapolando os fins para os quais foi inicialmente constituída e provocando seu estrangulamento estrutural. Em fins de 1926, amplo debate tomou as fileiras da imprensa paulista sobre a necessidade de criação de uma instituição permanente de defesa agrícola, causa que contou com a adesão das três principais associações de representação da lavoura: a Sociedade Paulista de Agricultura, a Liga Agrícola Brasileira e a Sociedade Rural Brasileira. Era o lobby do projeto esboçado por Arthur Neiva, que tramitava no Congresso Estadual de São Paulo. A despeito do apoio manifestado pela imprensa e pelas agremiações agrícolas, o projeto não foi aprovado, para consternação daqueles que lutavam para aliar à pujança material do café o cultivo e desenvolvimento das ciências. Para estes, a broca havia sido o alarme que indicara a necessidade premente de promoção de uma agricultura científica, em contraponto à prática extensiva, rotineira e predatória de cultivo. 
Em 1927, Júlio Prestes assumiu o governo de São Paulo, com Fernando Costa na pasta da agricultura. Ambos eram receptivos ao projeto do Instituto Biológico, reapresentado após modificação à Câmara dos Deputados. Já não mais se restringiria à defesa da agricultura, mas incluiria a defesa sanitária animal, estendendo o raio de ação da instituição à pecuária, ramo para o qual se direcionava cada vez mais avidamente o capital de cafeicultores preocupados em diversificar sua pauta de investimentos. Criado em 26 de dezembro de 1927, através da lei 2.243, o Instituto Biológico de Defesa Agrícola e Animal se inseriu num programa mais amplo de reformas encetado por Júlio Prestes na estrutura administrativa da agricultura. Em termos gerais, as medidas tomadas visaram promover a modernização e a diversificação agrícolas, a fim de atender às crescentes demandas do mercado interno e de fazer frente aos problemas econômicos postos pelo exclusivismo da monocultura cafeeira.

O Instituto Biológico teria como atribuições o estudo das questões concernentes à defesa agrícola e animal; o estudo e análise de produtos químicos (fungicidas, inseticidas, parasiticidas); a orientação dos produtores no combate às epifitias e epizootias; a preparação de soros e vacinas e outros produtos para diagnóstico, profilaxia e tratamento das doenças veterinárias; a divulgação dos estudos realizados; o intercâmbio com outros centros de pesquisa agrícola nacionais e estrangeiros e, por fim, a implementação de cursos práticos sobre as pesquisas desenvolvidas para leigos e especialistas (Ribeiro, 1997).

A direção do novo instituto foi entregue a Arthur Neiva, seu idealizador. Duas grandes divisões marcariam suas frentes de atuação: a Divisão de Defesa Vegetal, chefiada por Adalberto Queiroz Telles e onde ficaram alocados os membros da Comissão de Estudo e Debelação da Praga Cafeeira, agora extinta; e a Divisão de Defesa Animal, dirigida por Henrique da Rocha Lima. Como Neiva, Rocha Lima era um 'discípulo de Oswaldo Cruz', tendo sido da primeira geração de pesquisadores de Manguinhos, e voltava da Alemanha, onde desenvolvera grande parte de seus trabalhos científicos. A Divisão Animal - composta pelas seções de bacteriologia, fisiologia, anatomia patológica e entomologia e parasitologia animal - teria entre seus quadros muitos elementos oriundos do Instituto Oswaldo Cruz e de seu curso de aplicação.

A Divisão Vegetal, constituída pelas seções de entomologia e parasitologia agrícola e de química, contaria como sua principal atribuição o prosseguimento dos estudos sobre a broca, que grassava em muitos municípios do interior paulista, apresentando novamente altos índices de infestação em 1928. A Seção de Botânica e Agronomia herdou o herbanário, pertencente ao Museu Paulista, mas cuja origem remonta à Comissão Geográfica e Geológica de São Paulo. Quando Arthur Neiva esteve à frente do Serviço Sanitário de São Paulo, o herbanário foi 
incorporado ao Instituto Butantan, para o cultivo de plantas medicinais. A iniciativa não deu certo e o herbanário foi transferido para o Museu Paulista, a partir de onde foi transfe-rido para a nova instituição que se criara. Preocupado em afirmar a divulgação como marca da nova instituição, Neiva criou os Arquivos do Instituto Biológico.

O recrudescimento da broca em 1928 fez que novas alternativas para a campanha fossem aventadas. O controle biológico, método que consistia na introdução de inimigos naturais da praga nas culturas acometidas, utilizado com sucesso em países como os Estados Unidos, apareceu como meio viável de combate. O entomologista do Biológico Adolpho Hempel foi enviado em 1929 à Uganda, local de origem da broca, para estudar seus possíveis inimigos naturais. No mesmo ano, Hempel trouxe amostras da vespa-de-Uganda (Prorops nasuta), agente já utilizado nas Índias Holandesas para combater a broca. O controle biológico foi adotado como estratégia de combate, ao lado de práticas de controle recomendadas pela Comissão de Estudo e Debelação da Praga Cafeeira.

Empreendimento de longo prazo, o controle biológico pelos anos seguintes representou pauta privilegiada do Instituto. Experimentos para se determinar o melhor período de soltura das vespas, bem como a otimização das condições de criação ocupariam os técnicos do instituto pelas décadas de 1930 e 1940. Em 1939, as vespas distribuídas nas propriedades alcançariam o número de 2.492.324, sendo os agricultores incentivados a instalar seus próprios viveiros (Ribeiro, 1997, p. 66).

Arthur Neiva afastou-se da direção do Instituto em 1930, para assumir o cargo de secretário do interior de São Paulo. Ele deixou definitivamente de comandar a instituição em 1932, em razão de complicações políticas no conturbado cenário da revolução constitucionalista. Em janeiro de 1933, Henrique da Rocha Lima assumiu a direção, reforçando os vínculos entre o Biológico e Manguinhos, que marcariam a instituição pelos anos seguintes. A gestão de Rocha Lima foi acompanhada de intensificação das atividades do Instituto, num contexto diferente na agricultura paulista, no qual o padrão de desenvolvimento industrial passou a orientar a modernização do campo. Grande ênfase foi dada à pesquisa e produção de imunobiológicos, como a vacina anticarbunculosa, a maleína, o soro hemolítico para diagnóstico das salmoneloses, vacinas contra a bouba das galinhas, o garrotilho dos eqüinos e a tristeza bovina. Novos produtos químicos foram estudados para o combate a pragas da agricultura.

A crise econômica de 1929, provocada pela queda da bolsa de Nova York, trouxe sérias conseqüências para a cafeicultura paulista, que paulatinamente cedeu espaço a novas culturas, como a laranja. Para aproveitar a infra-estrutura implementada pelo café, houve expansão dessas culturas alternativas. Em 1934, no governo de 
Armando de Salles Oliveira, foi feita uma reforma no organograma do Instituto Biológico, com a criação das seções de Fisiologia Vegetal, Epifitias, Vigilância Sanitária Vegetal, Sorologia, Epizootias e Ornitopatologia. A defesa sanitária animal, atribuição da Diretoria de Indústria Animal do Ministério da Agricultura, passou a ser exclusivamente da alçada do Biológico.

A pauta de produtos desenvolvidos pelo Instituto ampliou-se consideravelmente. $\mathrm{O}$ ataque da broca na região cafeeira do extremo Oeste fez que o controle biológico ganhasse novo alento, com o envio de novas missões a Uganda para importação da vespa. Por sua vez, o desenvolvimento da cultura algodoeira assistido nos anos 30 fez que estudos sobre as pragas e doenças daquela planta ganhassem destaque.

O Biológico acompanhou pari passu o incremento da pecuária paulista, largamente impulsionada no pós-Primeira Guerra Mundial com a instalação de companhias frigoríficas. Os estudos sobre a avicultura, que contaram com o empenho de José Reis, constituíram uma das principais frentes de inovação do Instituto, ao lado de conquistas como a fabricação da vacina cristal violeta, contra a peste suína; a preparação da tuberculina para diagnóstico da tuberculose bovina, os estudos sobre a brucelose e a caracterização de doenças como a leprose da laranja, por Agesilau Bitancourt.

Em 1942, o Instituto Biológico passou por nova reorganização, na vigência da gestão de Paulo de Lima Corrêa na Secretaria de Agricultura, na interventoria Fernando Costa (1941-1945). Através dessa reforma criou-se uma terceira divisão - a Divisão de Biologia -, dedicada ao cultivo das ciências básicas e composta de nove seções: Parasitologia Vegetal, Parasitologia Animal, Bacteriologia, Vírus, Fisiologia Vegetal, Fisiologia Animal, Imunologia, Bioquímica e Farmacodinâmica e Higiene Comparada. Numa nova reforma empreendida cinco anos depois, a divisão de Biologia foi desmembrada, resultando na divisão de Biologia Animal e Vegetal.

No pós-guerra, o Biológico passou a acompanhar o novo perfil de atividade agrícola conferido pelo padrão industrial. Máquinas e implementos agrícolas e o desenvolvimento de novos produtos químicos, como defensivos, adubos e fertilizantes, orientaram a agricultura, subordinada à ordem industrial. $\mathrm{O}$ controle das pragas passou a privilegiar o método químico, com a criação de novos pesticidas. Das diversas campanhas feitas pelo Biológico na década de 1940, destacam-se novamente a broca do café, a saúva, a tristeza dos citros, a peste suína e a febre aftosa. Contra a broca do café, empregou-se o BHC aplicado através da pulverização ou polvilhamento. Em 1948, a aviadora brasileira Ada Rogato seria pioneira no emprego do avião em combate a uma praga agrícola, utilizando-o para a dispersão do inseticida entre os cafezais do noroeste paulista. Contra as pragas do algodoeiro utilizou-se 
também o BHC e o DDT, inseticida residual desenvolvido no pósguerra, que apresentaria grande potencial de ação. Inseticidas arsenicais como o verde-paris também surgiram como alternativas no combate a pragas da lavoura. Em 1948, os cientistas do Biológico isolaram a bradicinina, anti-histamínico presente no plasma sanguíneo quando do envenenamento por jararacas.

Os anos 50 e 60 assistiram ao aceleramento da industrialização do campo, cujo efeito colateral mais imediato foi o êxodo rural no interior paulista. Naquelas décadas, o Biológico ficaria sem a batuta de Rocha Lima, aposentado em 1949. Agesilau Antonio Bitancourt assumiria a direção, cuja marca foram os cursos de especialização oferecidos para agrônomos e veterinários recém-formados. A preocupação com as questões ambientais fez que cientistas do Biológico se voltassem para estudos sobre os resíduos de pesticidas. Nesse período, foi identificada no Instituto a doença de Newcastle.

Em 1970, uma reforma do Biológico subordina-o à Coordenadoria da Pesquisa Agropecuária, levando-o a perder suas principais atribuições - a defesa sanitária vegetal e animal - e desvinculando-o das condições históricas que lhe deram origem. Daí em diante, a trajetória do Instituto foi marcada por reveses como a extinção do Fundo de Pesquisa do Instituto Biológico e a gradual redução de verbas, com conseqüente evasão de pesquisadores. A despeito do quadro adverso, novas conquistas foram alcançadas, como a descoberta da clorose

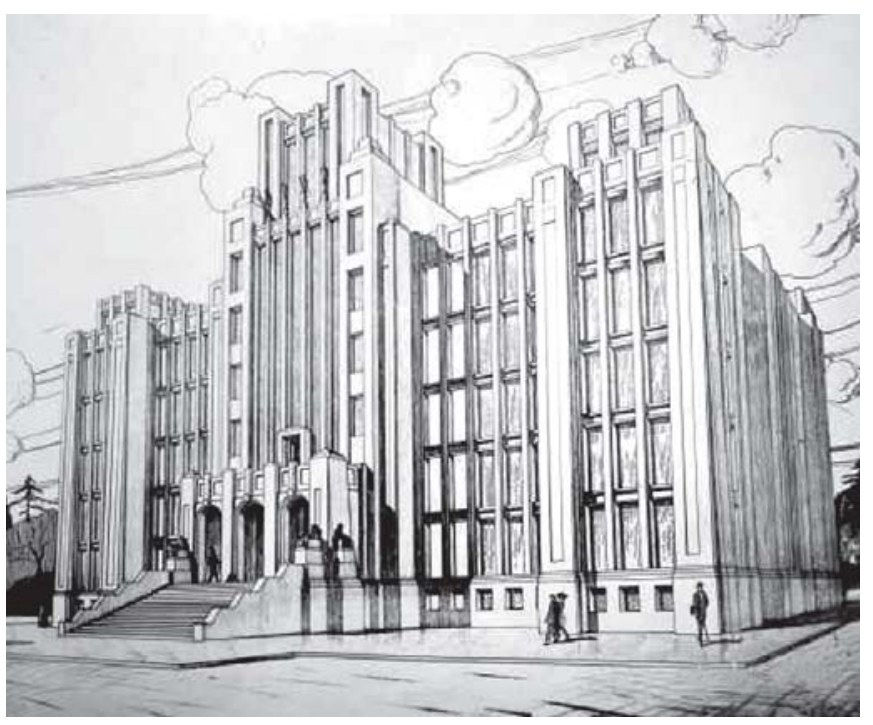

Projeto original do Instituto Biológico de São Paulo, feito pelo engenheiro Mário Whately e construído pela firma Dacio Moraes \& Cia.

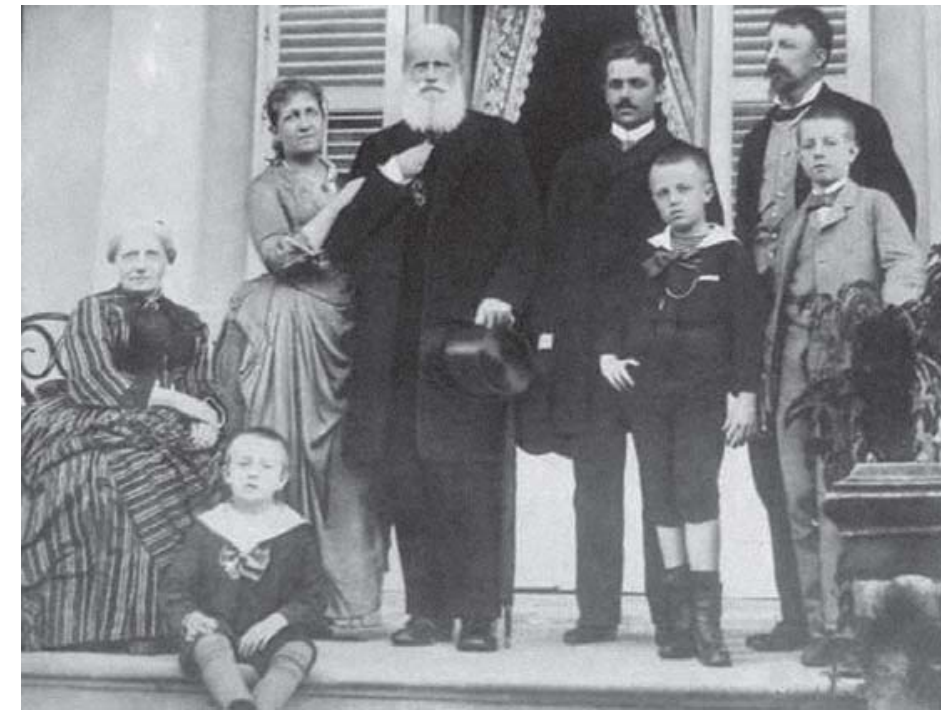

Retrato de dom Pedro II, ao lado da princesa Isabel. O segundo em pé, à direita, é o conde d’Eu. Imagem encontrada entre as fotos pessoais de Rocha Lima. Presume-se que ao lado direito de dom Pedro seja seu pai, Carlos Henrique da Rocha Lima, eminente clínico do império, e que uma das crianças seja Rocha Lima. 
variegada dos citros, pela pesquisadora Victoria Rossetti em 1993, a descrição do agente causador do amarelinho e a campanha contra o cancro cítrico.

Ainda em luta para preservar seu papel como produtor e divulgador das ciências agrícolas em São Paulo, o Instituto Biológico, em meio a dificuldades estruturais decorrentes dos baldos recursos que lhe são reservados, mantém-se como núcleo de excelência em pesquisas agronômicas e veterinárias. $\mathrm{O}$ resgate da memória documental e do histórico do Instituto ajuda a firmar seu papel proeminente no desenvolvimento da agropecuária paulista nos anos pretéritos, quando atuou em prol dos criadores e lavradores.

\section{Histórico do acervo}

Os documentos que compõem o acervo do Instituto Biológico remontam a 1924, quando da criação da Comissão de Estudo e Debelação da Praga Cafeeira. Criado em 1927, o Instituto Biológico inicialmente ficou disperso por diversas casas alugadas na capital paulista. A direção e a biblioteca do Instituto localizavam-se na avenida Brigadeiro Luiz Antonio, onde se acumulavam os livros, as publicações e os documentos oficiais despachados pelo diretor, Arthur Neiva.

Em 1937, por desígnio de Henrique da Rocha Lima, todas as seções do Instituto Biológico foram transferidas para o prédio-sede ainda
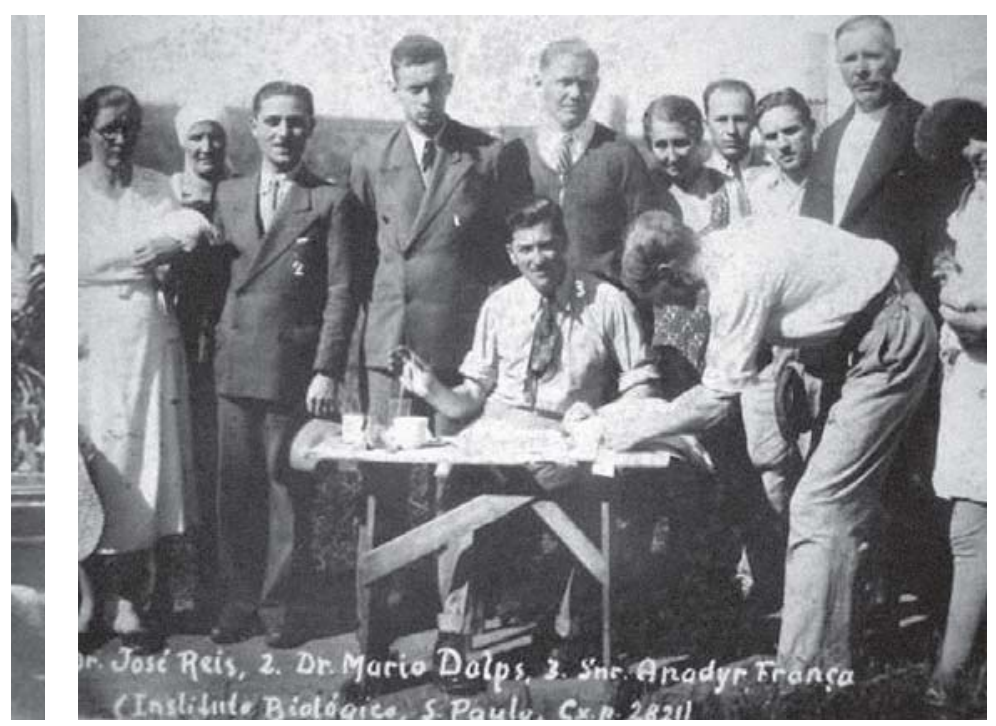

José Reis (sentado), fazendo demonstrações de experimentos em avicultura para os criadores.

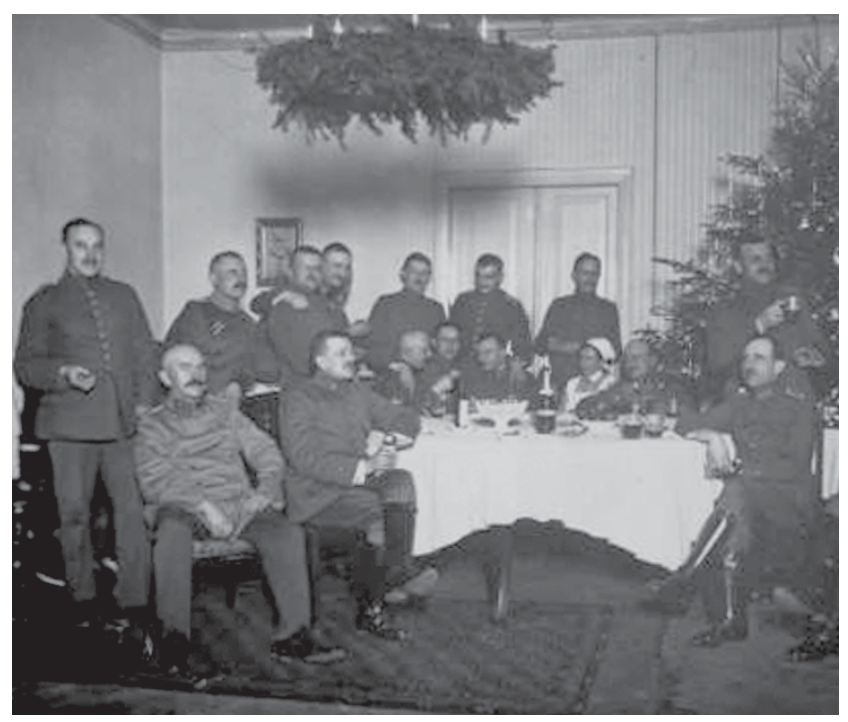

Militares alemães que participaram das batalhas da Primeira Guerra Mundial. O segundo, em pé, da direita para a esquerda, é Henrique da Rocha Lima que, juntamente com Stanislas von Prowazek, foi destacado em 1915 pelo governo alemão para estudar os surtos de tifo que acometeram os prisioneiros de guerra. 
em construção, por receio de que as tropas movimentadas por conta do golpe de 1937 ocupassem a edificação, assim como ocorrera em 1932. Somente em 1945 a nova sede seria oficialmente inaugurada. A documentação produzida e acumulada ficou espalhada entre as diversas seções que compunham o Instituto. Durante a reforma de 1947, criou-se a divisão de Ensino e Documentação Científica, voltada para o ensino, a divulgação e a gestão da biblioteca e dos museus, constituindo um núcleo de reunião de documentos institucionais, inclusive o arquivo fotográfico, sem, contudo, compor um acervo que reunisse toda a produção das diversas seções do Instituto.

A reunião da documentação iniciou-se por volta de 1961, quando começou a haver um esforço por parte de alguns pesquisadores em preservar a memória científica da instituição. Era habitual, quando da gestão de um novo diretor, a prática de fogueiras em fornos utilizados para esterilização da terra em experimentos da área vegetal, cujo combustível era a documentação institucional. Às escondidas, pilhas de papel acumuladas eram recolhidas antes de serem queimadas e armazenadas no sétimo andar do prédio principal.

Em 1995, o Centro de Atividades Técnicas Complementares, hoje Centro de Comunicação e Transferência do Conhecimento, pude sistematizar a atividade de constituição do acervo, conclamando pesquisadores de todas as seções do Instituto a enviarem material acumulado em seus laboratórios. Junto com muito 'entulho', vieram documentos interessantíssimos, aos quais foi somado o material encontrado no Museu de Anatomia Patológica, que incluía muitas fontes referentes a Rocha Lima.

Nas proximidades do septuagésimo aniversário do Instituto Biológico, em 1997, fui designada pela diretora Zuleide Alves Ramiro compôs uma comissão de comemoração. Com os documentos arrolados e a coleta de dados dos pesquisadores, foi possível a concretização de antigo projeto de composição de um livro sobre a história do Biológico, escrito por Maria Alice Rosa Ribeiro e lançado em 1997. Porém, o desordenamento da maior parte do material acumulado numa das salas do Instituto tornou possível à pesquisadora o estudo de ínfima fração dos documentos.

A gestão de Antonio Batista Filho, iniciada em 2004, constitui marco importante para a construção de nossa memória institucional, graças ao impulso dado para a organização do acervo, de modo que fique plenamente disponível e adequado para a pesquisa. Recentemente, cedeu-se amplo espaço para acomodação e acondicionamento da documentação.

Composto por 180 mil documentos textuais de cientistas desde o início do século $X X$ até recentemente, o acervo combina separatas de trabalhos publicados, relatórios das atividades, anotações de pesquisa, dossiês de quadros que pertenceram ao Instituto, palestras 
proferidas, além de correspondências entre cientistas brasileiros e estrangeiros. $\mathrm{O}$ acervo do Instituto Biológico inclui as coleções de Arthur Neiva, Henrique da Rocha Lima, José Reis, Agesilau Bitancourt, Veridiana Victoria Rossetti, Maurício Rocha e Silva, Maria Pereira de Castro, Antonio Baptista Filho, Benedicto Pedro Bastos Cruz, Vicente do Amaral, Waldyr Giorgi, Mario Autuori e Walkiria B. C. Moraes, além da coleção Arquitetura do Prédio do Instituto Biológico.

O acervo iconográfico reúne 60 mil fotografias e 70 mil slides em vidro, com registros de laboratórios, cientistas, plantas e animais com as mais diversas patologias, bem como imagens de experimentos realizados, meios privilegiados de se saber como se deu o processo de construção do conhecimento científico no Biológico. Muitos slides e cartazes permitem o estudo da história da divulgação científica, dimensão marcante durante toda a trajetória do Instituto Biológico, que remonta à campanha contra a broca chefiada por Neiva, sendo José Reis um de seus mais pronunciados defensores. O acervo contém grande parte do material de divulgação de José Reis, inclusive as várias reportagens que escreveu nos suplementos de ciência de diversos jornais, e algumas preciosidades, como o certificado do prêmio recebido por Rocha Lima na Alemanha Há ainda cerca de 3 mil documentos sobre a arquitetura e construção do prédio-sede do Biológico, projetado por José Maria Whitaker.

Apesar da riqueza do acervo, ainda lutamos pela aprovação do projeto para custeio dos serviços de organização arquivística e higienização, necessários para que esteja plenamente adequado à pesquisa acadêmica. O trabalho de organização está sendo desenvolvido com a constituição dos fundos Arthur Neiva e Henrique da Rocha Lima, os dois primeiros diretores da Instituição e responsáveis pela sua inserção e consolidação no cenário científico paulista.

\section{REFERÊNCIAS BIBLIOGRÁFICAS}

$\begin{array}{cl}\text { Fonseca, M. R. F. } & \begin{array}{l}\text { Fontes para a história das ciências da saúde no Brasil (1808-1930). } \\ 2002\end{array} \\ \text { História, Ciências, Saúde-Manguinhos, Rio de Janeiro, v. 9, suplemento, } \\ \text { p. 275-88. } \\ \text { Meloni, R. } & \begin{array}{l}\text { Ciência e produção agrícola: a Imperial Estação Agronômica de Campinas } \\ \text { (1887-1897). Dissertação de Mestrado, São Paulo, Faculdade de Filosofia, } \\ \text { Letras e Ciências Humanas, USP. }\end{array} \\ \text { Pestre, D. } & \begin{array}{l}\text { Por uma nova história social e cultural das ciências: novas definições, } \\ \text { novos objetos, novas abordagens. Cadernos IG-Unicamp, Campinas, v. 6, } \\ \text { n. 1, p. 3-56. }\end{array} \\ \text { Ribeiro, M. A. R. } & \begin{array}{l}\text { História, ciência e tecnologia: 70 anos do Instituto Biológico de São Paulo } \\ \text { na defesa da agricultura (1927-1997). São Paulo: Instituto Biológico. }\end{array}\end{array}$

Recebido para publicação em agosto de 2006. Aprovado para publicação em outubro de 2006. 


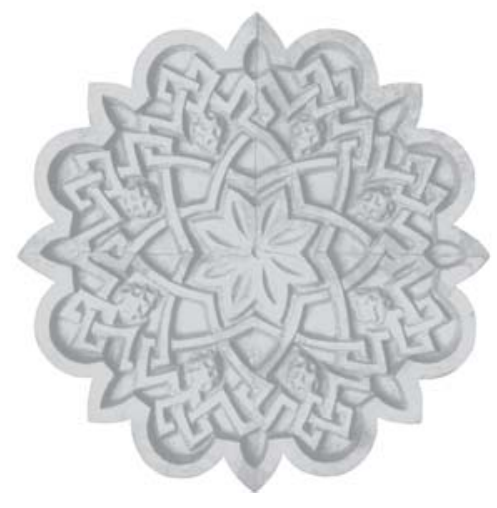

